Environment Conservation Journal 15(3)115-119, 2014

ISSN 0972-3099 (Print) 2278-5124 (Online)

Abstracted and Indexed

\title{
Dominance, diversity and evenness of Waterfowl: A case study of Sirpur tank, Indore (M.P.)
}

\author{
M. Malhotra', M.M. Prakash² and K. Pawar ${ }^{1} \bowtie$ \\ Received:08.02.2014 \\ Revised: 27.07.2014 \\ Accepted:02.11.2014
}

\begin{abstract}
The present paper deals with the Dominance, Diversity and Evenness of waterfowl observed during Oct. 2007 to Sept. 2009 at Sirpur lake (also known as Sirpur Tank), Indore. The highest Dominance, Diversity and Evenness was observed 0.0722 (March, 2008), 3.0449 (March, 2008) and 0.9100 (Jul, 2008) respectively, while lowest values of these indices were observed 0.2537 (Aug 2008), 1.2284 (Aug, 2009) and 0.5418 (Jan, 2009) respectively.
\end{abstract}

Keywords: Diversity, Dominance, Evenness, Sirpur tank, Waterfowl

\section{Introduction}

In simple meaning biodiversity refers richness, variation or number of different species of living organisms. It defines the stability of the ecosystem and evolution of the biosphere. Study of diversity help human society in various ways i.e. help in the maintenance of life sustaining ecosystem and play a substantial role in extending social, economic, scientific, educational, cultural, recreational and aesthetic devices. It also fulfills the food, shelter, health and other human needs (Sengupta and Bahdopathyay, 2005).The Sirpur (lake) tank comprises 57 species of waterfowl (Malhotra, 2005). Out of these 14 were migratory, 23 residents migrant and 24 Species were resident category. The diurnal and seasonal studies of waterfowl at sirpur lake discussed by Malhotra et al.( 2005, 2008, 2010). The waterfowl of migratory category spent their winter in and around the lake (Prakash et al., 2012). In the present study various diversity indices were calculated and discussed on the basis of Staub et al. (1970) proposed relationship between species diversity and pollution status.

\footnotetext{
Author's Address

${ }^{1}$ Department of Seed Technology, Government Holkar Science College, Indore, M.P., India.

${ }^{2}$ Department of Zoology, Government Holkar Science College, Indore M.P., India.

E-mail:mmpshrivastava@yahoo.co.in
}

\section{Material and Methods}

Identification of waterfowl was done with help of books Ali and Riplay (1983) and Ali (2002). Waterfowl were manually counted by walking on tank bank or boating from one corner of the tank to other with the help of high power binocular. The wetland (water body) selected for the present investigation is Sirpur Tank/lake. The important features which impress us to take up this water body as a study material were as follows:

1.It is a man-made perennial water body.

2.It is approachable conveniently.

3.It is open enough to get solar radiation.

4.It is being utilized for irrigation, fish culture and trapa culture.

5.It is habitat for various resident and migratory birds.

6.Bank side flora is rich and diversified to provide nesting or roosting place for birds.

7.A long time effort is being made to accord it a status of bird sanctuary.

8.It is an unprotected water body.

\section{History of Sirpur Tank}

Sirpur tank also known as Sirpur lake, is a manmade shallow tropical lake constructed in 1868 during regime of Holkar State for storage of runoff water in low line catchment area by earthen bund (Sharma and Belsare, 1997). According to the 
residents of Sirpur village and records at Municipal Corporation, Indore, it was originally a small natural water body and was renovated by the Holkar Maharaja in the year 1898. His Highness also constructed a small tank adjacent to the previous one to remove water scarcity problem.

\section{Location}

The Sirpur tank is located at the Sirpur Village (Tehsil and District, Indore, M.P.) on the left side of Indore-Dhar Road (NH-59) about $8 \mathrm{~km}$. west from the Indore city. Geographically, the Village is situated at $22^{\circ} 40^{\prime} \mathrm{N}$ latitude and $75^{\circ} 45^{\prime} \mathrm{E}$ longitudes. The MSL is 421 meter. (Figure 1).

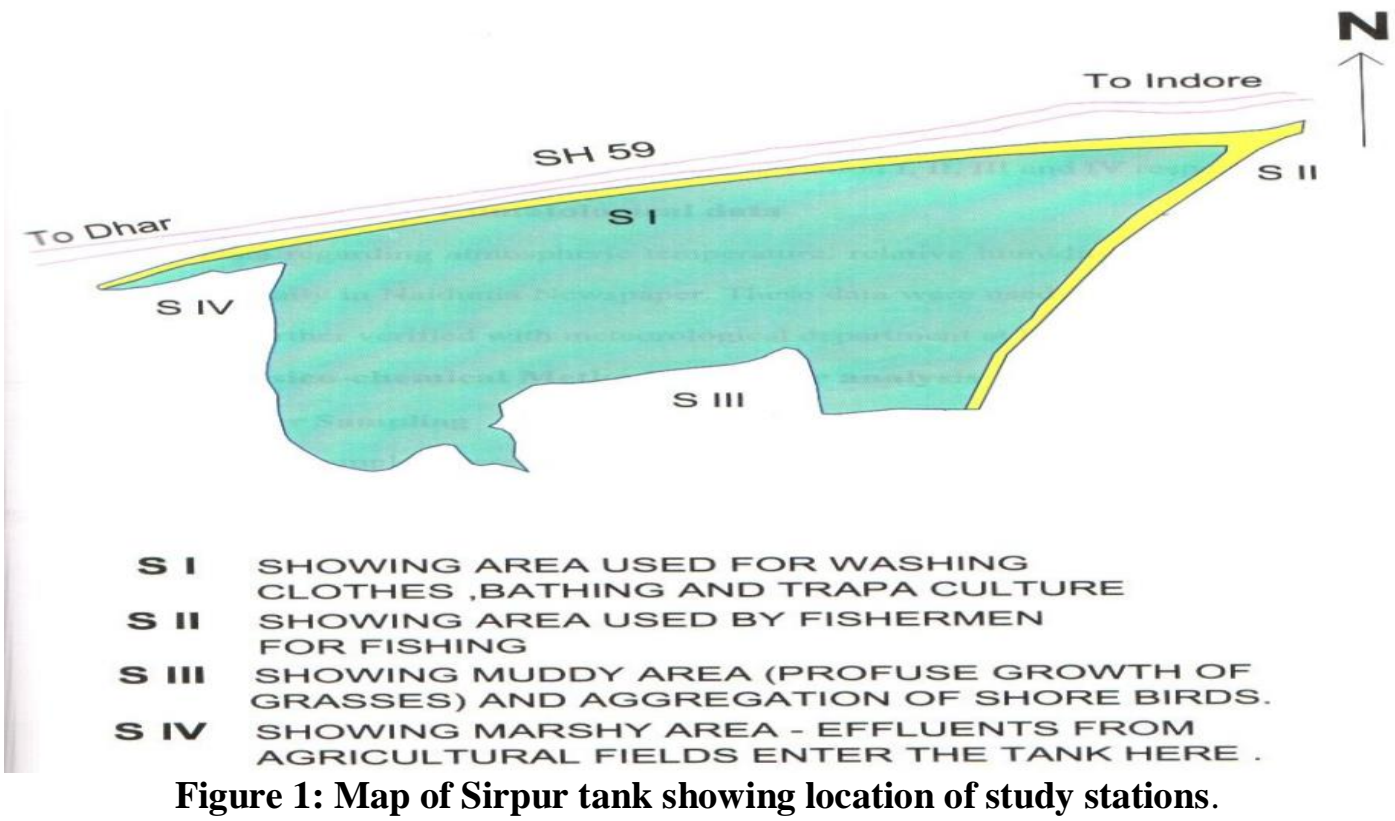

\section{Measurements}

The surface area of the tank is 20 sq. $\mathrm{km}$ with maximum and minimum depth $5 \mathrm{~m}$ and $1 \mathrm{~m}$ respectively. It covers $1,17,000$ ha at water spread area with $4.5 \mathrm{~km}$ long shore line (Sharma and Belsare, 1997). It has a constructed outlet with operational gate.

\section{Surroundings}

The perennial Sirpur tank is surrounded by human dwellings on three sides and agricultural fields on the remaining side i.e., South-East. The earthen boundary of the tank has plantation of large trees of 20 species. The bank side tree flora includes 277 plants belonging to 13 families (Malhotra, 2005). The quantitative characterization of waterfowl diversity in term of Dominance, Diversity and Evenness are calculated by using the following formulas -

\section{Shannon Diversity Index}

The Shannon and Weaver (1963) diversity index is designated

$$
\begin{aligned}
& \text { as } \bar{H} \text { or } \mathrm{H} \text {. It was calculated by following formula } \\
& \overline{\mathrm{H}}_{\text {Or H }}=\quad \sum_{\text {If ni/N } / \mathrm{N}) \log _{\mathrm{e}}(\mathrm{ni} / \mathrm{N})} \\
& \text { Then } \bar{H}_{\text {on } \mathrm{H}}=\quad \sum_{-} \text {pi loge pi }
\end{aligned}
$$

Where

$$
\begin{array}{lll} 
& & \overline{\mathrm{H}}_{\text {Or } \mathrm{H}=\text { Species Diversity }} \\
\mathrm{ni} & = & \text { Number of individuals in } \mathrm{i}^{\text {in }} \text { species } \\
\mathrm{N} & = & \text { Total number of individuals } \\
\mathrm{Pi} & = & \text { ni } / \mathrm{N} \text { is the probability of an individual to } \\
\text { belong to a species } &
\end{array}
$$

\section{Simpson Index of Dominance (1949)}

It is designated as ' $D$ ' and calculated by using following formula-

$$
\begin{array}{ll}
\mathrm{D} & =\sum_{(\mathrm{ni} / \mathrm{N})^{2}} \\
\mathrm{D} & =\sum_{(\mathrm{pi})^{2}}
\end{array}
$$




\section{Evenness Index}

Evenness index is also called Pielou's J (1966) and can be estimated as a ratio of the observed heterogeneity to the maximum possible heterogeneity.

$$
\mathrm{J}=\frac{\overline{\mathrm{H}}}{\mathrm{Ln}^{\mathrm{s}}}
$$

Where

$\begin{array}{lll}\mathrm{Ln} & = & \log \mathrm{e} \\ \mathrm{S} & = & \text { Number of species in the } \\ & \text { community }\end{array}$

\section{Result and Discussion}

Heywood and Baste (1995) have recognized three main elements/groups of biodiversity. These are organismal diversity, genetic diversity and ecological diversity. Ecological diversity includes both biological diversity (species richness) as well as habitat diversity (Singh, 2002). According to Gaston and Spicer (1998) this value of biodiversity can be divided in to two broad categories - use value and non- use value. According to Magurrah (1988) diversity may be used as an index of ecosystem well-being. The one area of application of ecological diversity is environmental monitoring, while other is nature conservation. It is very well accepted that species rich communities are better than poor ones. Conservational list almost invariably view, species diversity as species richness (Norton, 1986). Almost in all cases an increase in species diversity is considered as an increase in ecological quality (Magurran, 1988) also proposed a relationship between species diversity index and pollution status. They shows that when species diversity greater than 3 the pollution status is clear, when it is 1 to 3 the pollution status is moderately polluted and when is less than 1 it is consider as heavily polluted. Accordingly on the basis of species diversity index the Sirpur tank can be considered as moderately polluted during 2007-08 ( $\bar{H}$ 1.7-3.0) and 2008-09 ( $\bar{H}$ 1.2-2.7). Staubn et al. (1970) proposed another scale of pollution in term of species diversity which is slightly different from that of Wilhm and Dorris (1968). They suggested that when species diversity is between $3.5-4.5$ the water body is slightly polluted, when it is in between 2 - 3 the status is lightly pollution, when it is $1-2$ the status is considered as moderately polluted and if species diversity is in between $0-1$, the waterbody is heavily polluted. According to this scale too Sirpur tank can be considered lightly to moderately polluted waterbody. Pianka (1974) stressed on Simpson's dominance index which is dependent on sample size and reflects the proportional abundance of species richness and individual richness. In the present investigation this index varied from 0.0722 to 0.2537 during $2007-08$ and 0.1082 to 0.4694 during 2008-09. The diversity variation is on the basis of resources, resources utilization and niche overlap. Higher diversity values reflect diversified resources in the habitat available for components of the community. Decreased values of the species diversity indicated the increase in utilization of resources by an average species resulting into the lowering of the number of coexisting species or the amount of extent of niche overlap and affect the diversity. A community with greater niche overlap supports more species and vice versa (Mac Arthur, 1965, 1972). During the present study the Simpson diversity index varies from 0 to 1.0 , hence a value more than 0.5 can be considered as a higher value. According to Dash (2003) mature and stable communities in general have high diversity value (0.6 to 0.9). Serial communities or unstable communities and communities under severe stress exhibiting low diversity, usually show nearer to zero values (Odum, 1975). In the light of these facts it can be stated that as the habitat under study revealed low values of the species diversity therefore this can be considered as stressed and/or unstable community, which further confirmed the inference drawn from Shannon- Weaver Index. In the present investigation there was great variation in the total and species count during the various months which further confirmed its nature of unstable community. MacArther (1955) also reported that the greater fluctuation in species diversity of a community resulted in lesser stability. In the present investigation both Shannon-Weaver diversity index $\bar{H}=1.7028$ to $3.0449(2007-08)$ and 1.2284 to 2.6748 (2008-09) and Simpson diversity index D = 0.0722 to 0.2537 (2007-08) and 0.1082 to 0.4694 (2008-09), showed great monthly variation (Table 1 and 2). 
Malhotra et al.

Table -1 Dominance (D), Diversity $(\bar{H})$ and Evenness (E) of waterfowl at Sirpur Tank Indore during $2007-08$

\begin{tabular}{|l|l|l|l|l|l|l|}
\hline \multicolumn{4}{|c|}{ Observed Value } & \multicolumn{3}{c|}{ Calculated Value } \\
\hline S. No. & Month & $\begin{array}{l}\text { Total No. of } \\
\text { Birds }\end{array}$ & $\begin{array}{l}\text { Total No. of } \\
\text { Species }\end{array}$ & $\begin{array}{l}\text { Dominance } \\
(\mathbf{D})\end{array}$ & Diversity $\left(\mathbf{H}_{)}\right)$ & Evenness (J) \\
\hline 1 & Oct. 07 & 543 & 27 & 0.1071 & 2.6819 & 0.6139 \\
\hline 2 & Nov. 07 & 1803 & 40 & 0.2266 & 2.234 & 0.6056 \\
\hline 3 & Dec. 07 & 2240 & 45 & 0.1594 & 2.5935 & 0.6813 \\
\hline 4 & Jan. 08 & 2768 & 51 & 0.1006 & 2.9468 & 0.7988 \\
\hline 5 & Feb. 08 & 3538 & 54 & 0.0797 & 2.7897 & 0.6993 \\
\hline 6 & Mar. 08 & 2968 & 48 & 0.0722 & 3.0449 & 0.7865 \\
\hline 7 & Apr. 08 & 2548 & 34 & 0.0932 & 2.6801 & 0.7600 \\
\hline 8 & May 08 & 1760 & 29 & 0.1216 & 2.5339 & 0.7450 \\
\hline 9 & June 08 & 2074 & 30 & 0.1291 & 2.5108 & 0.7382 \\
\hline 10 & July 08 & 333 & 11 & 0.1257 & 2.184 & 0.9100 \\
\hline 11 & Aug. 08 & 118 & 8 & 0.2537 & 1.702 & 0.8188 \\
\hline 12 & Sept. 08 & 117 & 8 & 0.1883 & 1.8563 & 0.8927 \\
\hline
\end{tabular}

Table- 2Dominance (D), Diversity $(\bar{H})$ and Evenness (E) of waterfowl at Sirpur Tank Indore during $2008-09$

\begin{tabular}{|l|l|l|l|l|l|l|}
\hline \multicolumn{5}{|c}{ Observed Value } & \multicolumn{3}{c|}{ Calculated Value } \\
\hline S. No. & Month & $\begin{array}{c}\text { Total No. } \\
\text { of Birds }\end{array}$ & $\begin{array}{c}\text { Total No. } \\
\text { of Species }\end{array}$ & $\begin{array}{c}\text { Dominance } \\
(\mathbf{D})\end{array}$ & Diversity $\left(\vec{H}_{)}\right)$ & Evenness (J) \\
\hline 1 & Oct. 08 & 177 & 15 & 0.1210 & 2.3076 & 0.8521 \\
\hline 2 & Nov. 08 & 936 & 27 & 0.1286 & 2.5346 & 0.769 \\
\hline 3 & Dec. 08 & 1763 & 41 & 0.1376 & 2.6748 & 0.7202 \\
\hline 4 & Jan. 09 & 2835 & 51 & 0.1138 & 2.1303 & 0.5418 \\
\hline 5 & Feb. 09 & 3499 & 54 & 0.1082 & 2.72 & 0.6820 \\
\hline 6 & Mar. 09 & 3216 & 44 & 0.1376 & 2.6074 & 0.6821 \\
\hline 7 & Apr. 09 & 2055 & 33 & 0.1478 & 2.4282 & 0.6944 \\
\hline 8 & May 09 & 2012 & 31 & 0.1489 & 2.3095 & 0.6725 \\
\hline 9 & June 09 & 1881 & 30 & 0.1445 & 2.3489 & 0.6906 \\
\hline 10 & July 09 & 303 & 11 & 0.1801 & 1.9965 & 0.8329 \\
\hline 11 & Aug. 09 & 97 & 8 & 0.4694 & 1.2284 & 0.5908 \\
\hline 12 & Sept. 09 & 103 & 8 & 0.2403 & 1.7408 & 0.8371 \\
\hline
\end{tabular}

According to Dash (2003) near zero values of respectively, where the number of species was 48 Simpson index are obtained when numerous and 54 respectively. These differences may be due species are present. In the present investigation too, to absence of few species at time of recording or lower value of Simpson index (0.1082) corresponds author may not reached of these species due to vast with the highest number of species (54) and highest area of studied waterbody. Highest value value of Simpson index (0.4694) corresponds with $0.2537(2007-08)$ of Simpson index corresponded to the lowest number of species (8) during 2008-09. the lowest number (8) of species (Table 1 and 2).

However, a slight deviation was observed in 2007- The Evenness of species depends upon the degree 08 when lowest values of this index were observed of distribution of different species, which ultimately as 0.0722 and 0.0792 in March and February affects its diversity (Verma, 2002). In the present 
investigation, during 2007-08 maximum (0.9100) and minimum (0.6056) degree of evenness were observed in July and November respectively, while during 2008-09 maximum (0.8521) and minimum (0.5418) degree of Evenness was observed in October and January respectively. Generally lower value of Evenness corresponds with higher number of species and vice versa, higher the value of Evenness the lesser is the number of species (Table 1 and 2).

\section{References}

Ali, S., 2002. The book of Indian birds. $13^{\text {th }}$ edition. Bombay Nat. Hist. Soc.. Oxford university press, Newyork.Ali, S. and Repley, S. D., 1987. Hand book of the birds of India and Pakistan. Oxford university press, Newyork.

Dash, M.C., 2003. Fundamentals of ecology. $2^{\text {nd }}$ Edition Tata McGrew - Hill Publishing Company Limited. New Delhi.

Gaston, K.J. and Spicer, J.I., 1998. Biodiversity, An introduction. Blackwell, Science Ltd. Oxford, PP. 113.

Heywood, V. H. and Baste, J., 1995. Introduction in global biodiversity assessment (ed. V. h. Heywood). Camdridge University press, Cambridge. pp. 1-19.

Mac Arthur, R. H., 1955. Fluctuation of animal Population and a measure of community stability. Ecology 36:533-536.

Mac Arthur, R.H., 1965. "Patterns of species diversity." Biol. Rev . 40: 510: 533.

Mac Arthur, R.H., 1972. Geographical ecology "Patterns in the distribution of species.' " Harper and Row New York pp 269.

Magurran, A.E., 1988. Ecological biodiversity and its measurement. Croom Helm. Ltd. London, PP. 179.

Malhotra, M., 2005. Studies on the diversity of aquatic avifauna and flora of sirpur tank, Indore. Ph. D. Thesis D.A.V.V. Indore. (M.P.) India.

Malhotra, M., Prakash, M. M. and Pawar, K., 2005. Dial variation in waterfowl during winter at Sirpur Tank, Indore (M.P.). Indian J. Environ and Ecoplan 10(1): 129-138.
Malhotra, M., Prakash, M.M. and Pawar, K., 2008. Waterfowl population and their variation during summer at Sirpur Tank, Indore. Journal of Ecobiology 22(1) 63-71.

Malhotra, M., Prakash M.M. and Pawar, K., 2010. Seasonal diversity of waterfowl belonging to family Anatidae of Sirpur Tank, Indore. Ind. Res. Comm. Vol. 4 (2): 174-176.

Norton, B.G., 1986. The preservation of species. Princeton University Press, Princeton.

Odum, E.P., 1975. Fundamentals of ecology. $3^{\text {rd }}$ Ed. W.B. Saunders company, Philadelphia and London.pp 574.

Pielou, E. C., 1966. The measurement of diversity in different types of bological collections. J. Biol. 13: 131-144.

Pianka, E.R., 1974. "Neche overlap and diffuse competition" Proc. Nat. Acad. Sci. USA. 71: 2141-2146.

Prakash, M.M., Malhotra, M. and Pawar, K., 2012. Threatened wetland birds at Sirpur lake. Indore (M.P.). Environment Conservation Journal 13(1\&2):133-135.

Sengupta, N. Bandhopadhyay, 2005. Biodiversity and quality of life. MacMillan, India Publisher, New Delhi pp. ix

Sharma, S. and Belsare, D.K., 1997. A checklist of waterfowl of Sirpur lake. Ind. J. Spect. 9 (2): 39-42.

Shannon, C.E. and Weaver, W., 1963. The mathematical theory of communication. University Illinois Press, Urbana.

Simpson, E. H., 1949. Measurement of diversity. Nature 163168.

Singh, H.R., 2002. Ecological diversity of Hill streams. In Eco. and Cons. of lakes reservior and rivers. $\mathrm{ABD}$ publisher, Jaipur, India. PP. 74-78.

Staub, R. Appling, J.W., Hatstetter, A.M. and Hass, I.J., 1970. The effects of industrial waste of memphis and shelby country on primary planktonic producers. Bioscience 20: 905-912.

Verma, P.K., 2002. Limnological investigation of Badua reservoir with reference to fish production and conservation, Bhagalpur (Bihar) India. In Eco. and Cons. of lakes res. and rivers. ABD publishers Jaipur (India). pp. 105-135. 